\title{
Plutonium Silicate Alteration Phases Produced by Aqueous Corrosion of Borosilicate Glass
}

\author{
J. A. Fortner, C. J. Mertz, A. J. Bakel, R. J. Finch, and D. B. Chamberlain
}

\author{
Chemical Technology Division \\ ARGONNE NATIONAL LABORATORY \\ 9700 South Cass Avenue \\ Argonne, IL 60439-4837
}
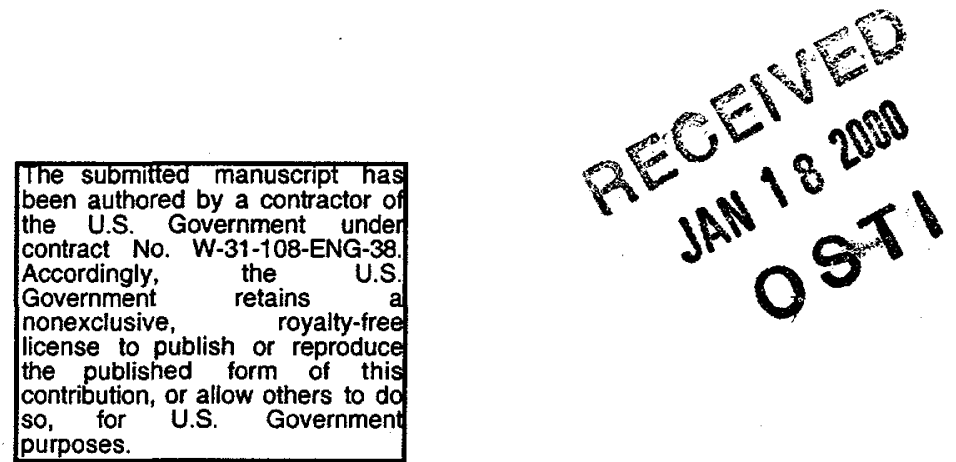

For presentation at

Scientific Basis for Nuclear Waste Management XXII

Materials Research Society 1999 Fall Meeting

November 30 to December 4, 1999

Boston, Massachusetts 


\section{DISCLAIMER}

This report was prepared as an account of work sponsored by an agency of the United States Government. Neither the United States Government nor any agency thereof, nor any of their employees, make any warranty, express or implied, or assumes any legal liability or responsibility for the accuracy, completeness, or usefulness of any information, apparatus, product, or process disclosed, or represents that its use would not infringe privately owned rights. Reference herein to any specific commercial product, process, or service by trade name, trademark, manufacturer, or otherwise does not necessarily constitute or imply its endorsement, recommendation, or favoring by the United States Government or any agency thereof. The views and opinions of authors expressed herein do not necessarily state or reflect those of the United States Government or any agency thereof. 


\section{DISCLAIMER}

Portions of this document may be illegible in electronic image products. Images are produced from the best available original document. 


\title{
Plutonium Silicate Alteration Phases Produced by Aqueous Corrosion of Borosilicate Glass
}

\author{
J. A. Fortner, C. J. Mertz, A. J. Bakel, R. J. Finch, and D. B. Chamberlain \\ Chemical Technology Division, Argonne National Laboratory, Argonne, IL 60439
}

Borosilicate glasses loaded with $\sim 10 \mathrm{wt} \%$ plutonium were found to produce plutoniumsilicate alteration phases upon aqueous corrosion under a range of conditions. The phases observed were generally rich in lanthanide $(\mathrm{Ln})$ elements and were related to the lanthanide orthosilicate phases of the monoclinic $\mathrm{Ln}_{2} \mathrm{SiO}_{5}$ type. The composition of the phases was variable regarding $[\mathrm{Ln}] /[\mathrm{Pu}]$ ratio, depending upon type of corrosion test and on the location within the alteration layer. The formation of these phases likely has implications for the incorporation of plutonium into silicate alteration phases during corrosion of titanate ceramics, high-level waste glasses, and spent nuclear fuel.

Monolithic samples of a lanthanide borosilicate (LaBS) glass loaded with 10 weight $\%$ plutonium were reacted with water vapor at $100 \%$ relative humidity and $200^{\circ} \mathrm{C}$ for periods of 14 to 56 days. The test procedure is described in detail elsewhere [1,2]. Parallel corrosion tests, whereby crushed LaBS glass was immersed in deionized water at $90{ }^{\circ} \mathrm{C}$ (a modified ASTMC-1285 Product Consistency Test or PCT), were conducted for extended periods of time ( $>98$ days). The surfaces of the glass samples, along with alteration phases, were examined with a transmission electron microscope (TEM) and scanning electron microscope (SEM) to determine the characteristic alteration products. Vapor alteration of the LaBS glass for 14 days produced macroscopic crystallites of a plutoniumlanthanide silicate material, which is, to our knowledge, the first plutonium-based alteration phase observed in glass-water reaction. An extensive alteration layer was found on the glass surface containing amorphous aluminosilicate layered with bands of a cryptocrystalline plutonium- lanthanide silicate that was similar to the surface crystals but relatively depleted in lanthanides. Of particular interest was evidence of size selection among the lanthanide elements lanthanum, neodymium, and gadolinium, as well as separation of the lighter lanthanides from plutonium. There is little evidence that gadolinium, an important neutron absorber, is separated from the plutonium.

The LaBS glass is chemically durable and can dissolve substantial amounts of plutonium as well as the neutron absorbers gadolinium and hafnium $[2,3,4]$. The prototype LaBS formulation tested in this work, however, contained no hafnium but did contain some zirconium, which is expected to be similar chemically. Although a titanate ceramic has been chosen over the LaBS glass as a plutonium immobilization form [5], the corrosion mechanisms observed in testing of the LaBS glass may provide insight into the behavior of plutonium and lanthanide elements during alteration of other waste forms. Specifically, silicon-rich groundwater may be available to alter waste forms in the proposed Yucca Mountain repository, a site located in a hydrologically unsaturated zone and composed of welded and devitrified tuff. The local groundwater from the nearby USGS J-13 well contains $\sim 40 \mathrm{ppm}$ dissolved silica. Silicon-rich groundwater has been found to cause lowtemperature alteration of natural zirconolites [6], an observation with direct bearing on the long-term behavior of the titanate phases in the target plutonium immobilization ceramic. Plutonium is also an important constituent of spent nuclear fuel and is a trace element in high-level waste (HLW) glass. Corrosion tests of $\mathrm{HLW}$ glass indicate that released plutonium is associated with colloidal particles, which are dominated by smectite-clays (a silicate). Silicon-based colloids have been implicated in the migration of spent weapons plutonium from the Nevada Test Site [7], although Kersting $e t$ al. attributed the plutonium incorporation to sorption rather than co-precipitation. 
After vapor hydration at $200^{\circ} \mathrm{C}$ and $100 \%$ relative humidity for 14 days, the surface of the LaBS glass monolith was speckled with minute $(\sim 5 \mu \mathrm{m})$ crystallites that appeared white against the dark glass. The surface of the glass itself had a slight crust, or alteration film, which appeared less advanced than what would typically be observed from a similar test on a HLW glass. Samples of the white surface crystallites were embedded in epoxy resin and thin sectioned with a Riechert ultramicrotome. The thin-sectioned material was examined using a JEOL 2000FX II transmission electron microscope operating at $200 \mathrm{keV}$ and equipped with $\mathrm{x}$-ray (EDS) detectors and an electron energy loss spectrometer (EELS). Cross sections of the altered surface film on the glass were taken by scoring the specimen with a diamond scribe, and embedding fractured material for thin sectioning in a manner similar to the surface particles. Intact glass surfaces were also examined with an SEM and light microscopy. Samples of LaBS glass from crushed glass immersion tests at $90^{\circ} \mathrm{C}$ were also examined. The LaBS glass reacted very slowly under these conditions, and little evidence of an alteration layer was observed until at least 98 days of testing. Longer-term tests have not been examined in detail owing to a shift in program focus to the titanate ceramic waste forms [5]. In each case where lanthanide-silicate alteration products were observed, the details of their structure and composition were dependent upon test type, test duration, and even location within or upon the altered glass surface.

The SEM examination of glass monolith surfaces from vapor hydration testing revealed copious particles of a lanthanide ( $\mathrm{La}, \mathrm{Nd}$, and $\mathrm{Gd}$ ) plutonium silicate composition, distinct from the LaBS glass (Figure 1). These particles typically had a rosette or "onion-skin" structure, and were loosely attached to the glass surface. These particles are the white microcrystals observed visually and sampled for TEM as described above.

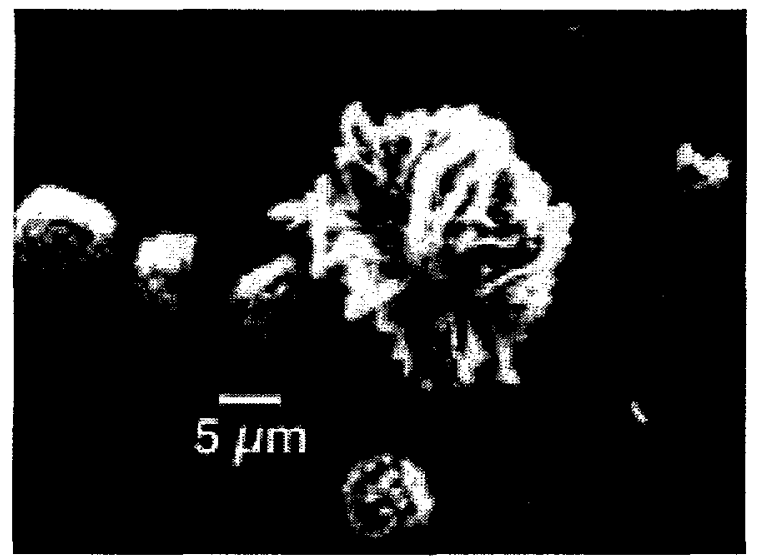

Figure 1. SEM backscatter micrograph of a plutonium silicate "rose" from LaBS vapor alteration at $200^{\circ} \mathrm{C}$.

The TEM revealed a sharp, crystalline diffraction from the surface particles clearly distinct from that of Ln oxides, Ln oxyhydroxides, Ln-uranium oxides, or $\mathrm{PuSiO}_{4}$ (where $\mathrm{Ln}=$ lanthanide). The experimentally-derived $d$-spacings are compared with JCPDS-ICDD diffraction data for two $\mathrm{Ln}_{2} \mathrm{SiO}_{5}$ structures in Table 1 [8]. Both EDS (Figure 2) and EELS (Figure 3) suggest a composition enriched in the larger lanthanides ( $\mathrm{La}>\mathrm{Nd}>\mathrm{Gd}$ ), depleted in silicon and nearly devoid of aluminum relative to the LaBS glass. The low energy EELS signal from boron, readily detected in the glass, was not observable from the crystals. Interestingly, the ratio of the plutonium to gadolinium remained about the same from the glass to the alteration crystal for both EDS and EELS measurements (Figures 2 and 3). Along with the diffraction data, we are led to propose a lanthanide-silicate type structure, with plutonium and gadolinium occupying a similar site in the structure. The mechanism driving size selectivity favoring the larger lanthanum and neodymium ions in this structure is unknown. 


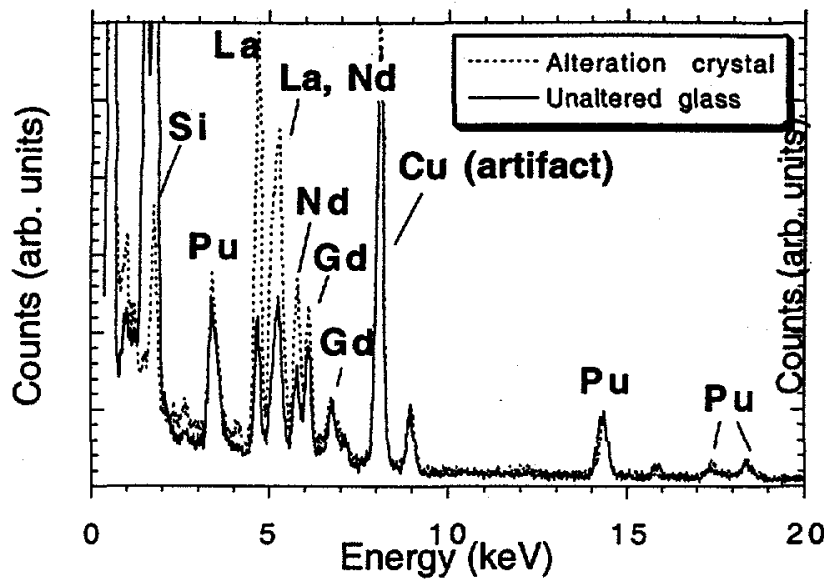

Figure 2. Energy dispersive spectrum from the large Pu-lanthanide-silicate crystals from the 14-day vapor hydration test. The EDS spectrum from unaltered LaBS glass is shown for comparison, normalized to the $\mathrm{Pu}$ signal.

Table 1. Electron diffraction results from the surface crystal from a 14-day vapor hydrated LaBS. Reference JCPDS-ICDD [8] data reported for $I / I_{0} \geq 0.3$ or for match with experiment.

\begin{tabular}{ccc}
\hline $\begin{array}{c}\text { Experimental } \\
\text { d-spacings } \\
(\mathrm{nm})\end{array}$ & $\begin{array}{c}\mathrm{Nd}_{2} \mathrm{SiO}_{5} \\
\mathrm{JCPDS}-\mathrm{ICDD} \\
40-284 \\
(\mathrm{~nm})\end{array}$ & $\begin{array}{c}\mathrm{La}_{2} \mathrm{SiO}_{5} \\
\mathrm{JCPDS}-\mathrm{ICDD} \\
40-234 \\
(\mathrm{~nm})\end{array}$ \\
\hline & 0.5591 & 0.572 \\
0.489 & 0.4859 & \\
& 0.4382 & 0.4418 \\
0.387 & 0.3891 & 0.3805 \\
0.351 & 0.3413 & 0.3511 \\
& $0.3180,0.3128$ & \\
0.286 & $0.2937,0.2853$ & $0.2992,0.2945$ \\
& 0.2788 & $0.2850,0.2831$ \\
0.260 & 0.2604 & 0.2652 \\
0.245 & 0.2467 & 0.2450 \\
0.224 & $0.2215,0.2264$ & $0.2202,0.2192$ \\
0.202 & 0.20046 & $0.2035,0.1984$ \\
& 0.19357 & \\
0.187 & 0.18678 & 0.1877 \\
0.176 & 0.17535 & 0.17699 \\
0.1652 & 0.16580 & 0.16555 \\
0.1549 & 0.15450 & 0.15641 \\
0.1487 & 0.14892 & 0.14729 \\
\hline
\end{tabular}

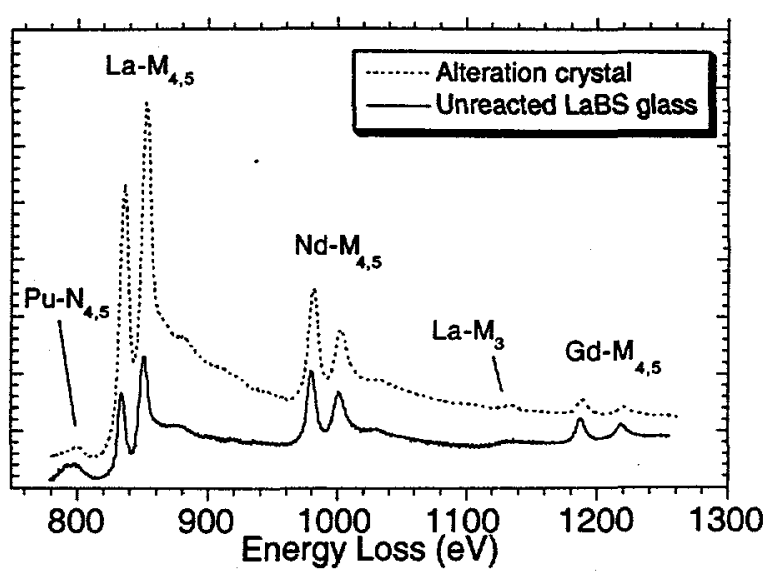

Figure 3. Electron energy loss spectra (EELS) of surface material from the 14-day vapor hydration of LaBS glass. The spectra reveal different partitioning of the rare earth elements ( $\mathrm{La}, \mathrm{Nd}$, and $\mathrm{Gd}$ ) in the crystalline alteration phase than in the unaltered glass.

Table 2. Electron diffraction results from intralayer crystallites from the 14-day vapor hydrated LaBS. Reference JCPDS-ICDD [8] data reported for $I / I_{0} \geq 0.3$ or for match with experiment.

\begin{tabular}{cc}
\hline $\begin{array}{c}\text { Experimental } \\
\text { d-spacings } \\
\mathrm{C} 18500 \\
(\mathrm{~nm})\end{array}$ & $\begin{array}{c}\mathrm{Nd}_{2} \mathrm{SiO}_{5} \\
\text { JCPDS-ICDD } \\
40-284 \\
(\mathrm{~nm})\end{array}$ \\
\hline & 0.5591 \\
& 0.4859 \\
& 0.4382 \\
0.339 & 0.3891 \\
$0.310,0.307$ & 0.3413 \\
& $0.3180,0.3128$ \\
0.275 & 0.2788 \\
& 0.2604 \\
0.243 & 0.2467 \\
& $0.2215,0.2264$ \\
0.196 & 0.20046 \\
0.192 & 0.19357 \\
& 0.18678 \\
0.170 & 0.17535 \\
$0.166,0.163$ & 0.16580 \\
\hline
\end{tabular}

Cross sections of the surface film were then examined by TEM, revealing a complex alteration structure tenaciously bonded to underlying LaBS glass (Figure 4). Within the 
alteration layer were very small crystallites having a similar lanthanide plutonium silicate composition. The crystallites were imbedded in a matrix of a fibrous aluminosilicate phase, which appeared similar to the mineral imogolite $\left(\mathrm{Al}_{2} \mathrm{SiO}_{3}(\mathrm{OH})_{4}\right)[9]$. Electron diffraction from the intralayer lanthanide plutonium silicate crystals revealed a less ordered, perhaps cryptocrystalline pattern, with only a few $d$-spacings identifiable. These are tabulated in Table 2 for several diffraction pattern measurements. Notably, EDS indicated that these intralayer crystals were less enriched in the lighter lanthanides than were the surface crystals. This is reflected by a systematic shift in the observed d-spacings to higher values, owing to the larger ionic size of the lighter lanthanides. This is illustrated in Figure 5, where $d$-spacings are plotted against $\operatorname{Ln}$ ions and experimental values $[8,10]$.

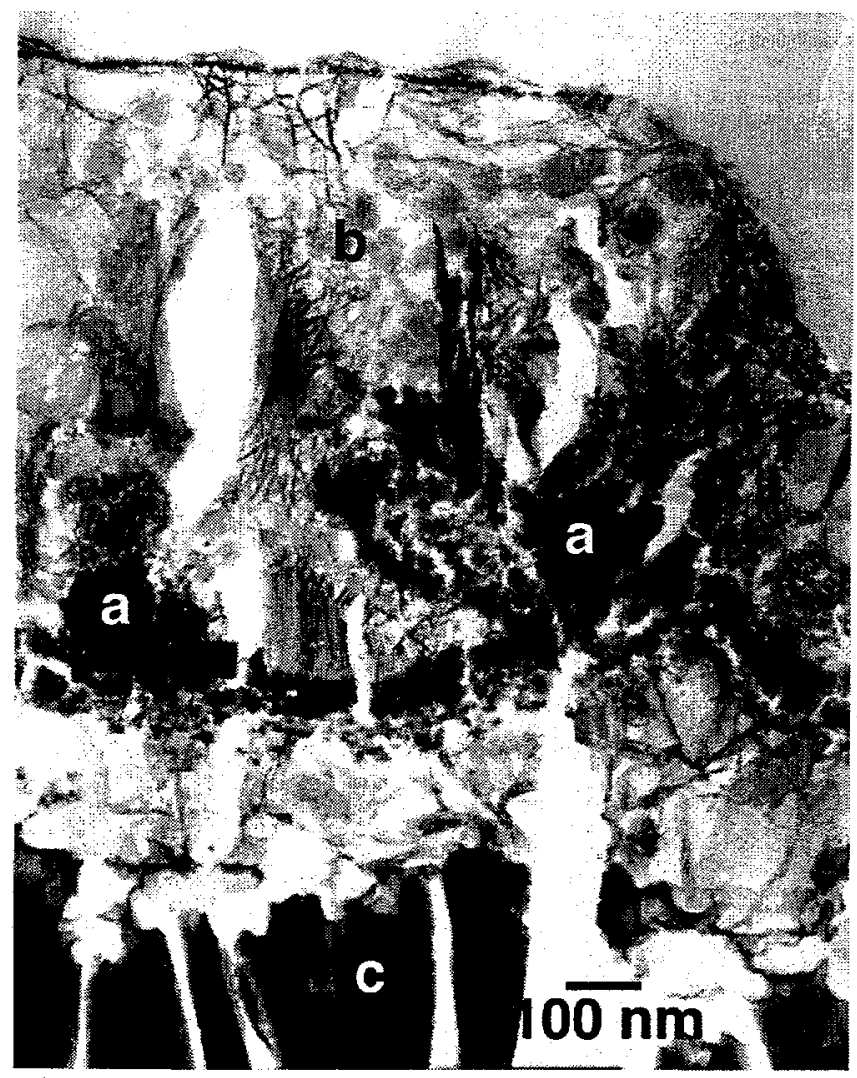

Figure 4. Transmission electron micrograph of the surface alteration layer on LaBS glass from a 14-day vapor hydration test showing (a) crystalline Pu silicates (b) aluminosilicate regions, and (c) unaltered LaBS glass. The "picket fence" appearance of the glass is an artifact of the microtoming.

Samples of the modified (98-day) PCT-reacted samples were examined by TEM (Figure 6). Generally, the LaBS glass reacted very slowly under these conditions relative to $H L W$ type glasses, likely owing to the absence of alkali oxides in the LaBS [2]. Only a slight hint of surface alteration could be observed, along with occasional minute $(<100 \mathrm{~nm})$ alteration products of plutonium lanthanide silicate. These alteration products produced no crystalline diffraction pattern, and were likely amorphous. Nonetheless, their chemical composition strongly suggests that they are structurally related to the larger crystals observed in the more aggressive vapor hydration conditions.

The gadolinium orthosilicate phase of the monoclinic $\mathrm{Ln}_{2} \mathrm{SiO}_{5}$ type has been characterized by Smolin and Tkachev [10]. These phases have a layered structure similar to the synthetic titanites. In the proposed structure (figure 7), the Ln (or plutonium, in the present case) occupies two distinct sites, the six-coordinated octahedral sites and the seven-fold decahedral sites. The $\mathrm{SiO}_{2}$ tetrahedra share three oxygen atoms with the octahedral lanthanide and one oxygen with the decahedral lanthanide. To our knowledge, these phases have not previously been synthesized except at high temperature from melts. However, the 
presence of a long $\mathrm{Si}-\mathrm{O}$ bond in the decahedral site [10], which can be replaced by $\mathrm{Si}-\mathrm{OH}$ in hydrous minerals, makes the low temperature synthesis of this phase plausible.

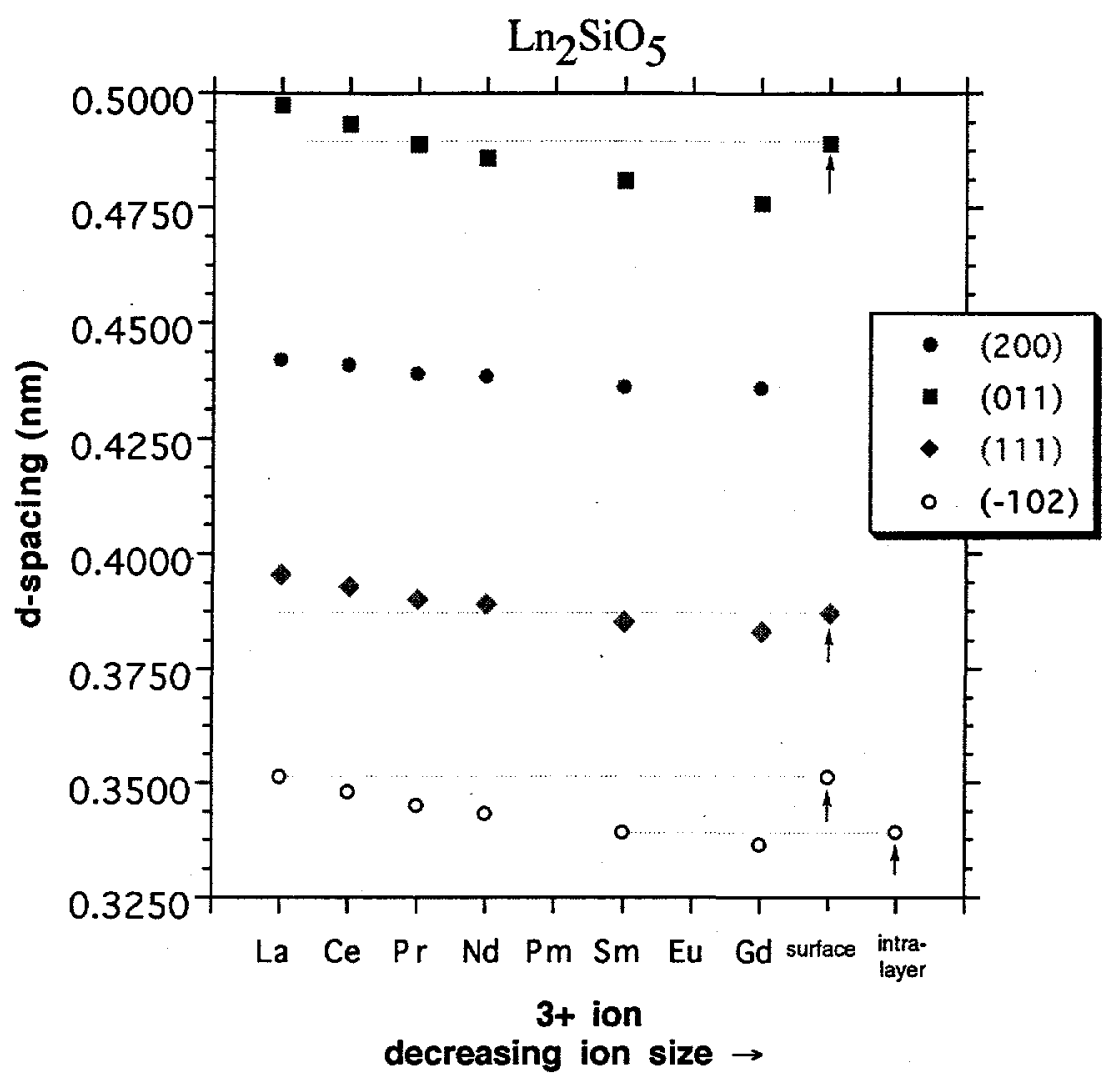

Figure 5.

Experimental dspacings (horizontal lines with data from this study marked by arrows) for surface and intralayer crystals from the 14-day vapor hydration test. These are compared with literature values $[8,10]$ for $\mathrm{Ln}_{2} \mathrm{SiO}_{5}$ structures as a function of $3+$ ion size.

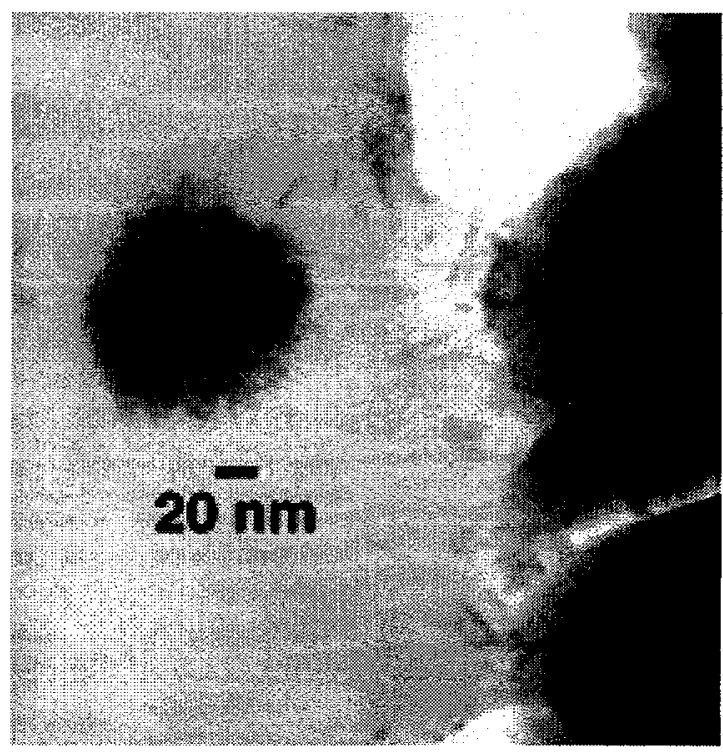

Figure 6. A TEM micrograph of a plutonium silicate alteration phase from a 98-day immersion test of $\mathrm{LaBS}$ glass at $90^{\circ} \mathrm{C}$. This phase appears as a small clump at left. The glass (right) is accompanied by wisps of aluminum-rich debris from the surface. 


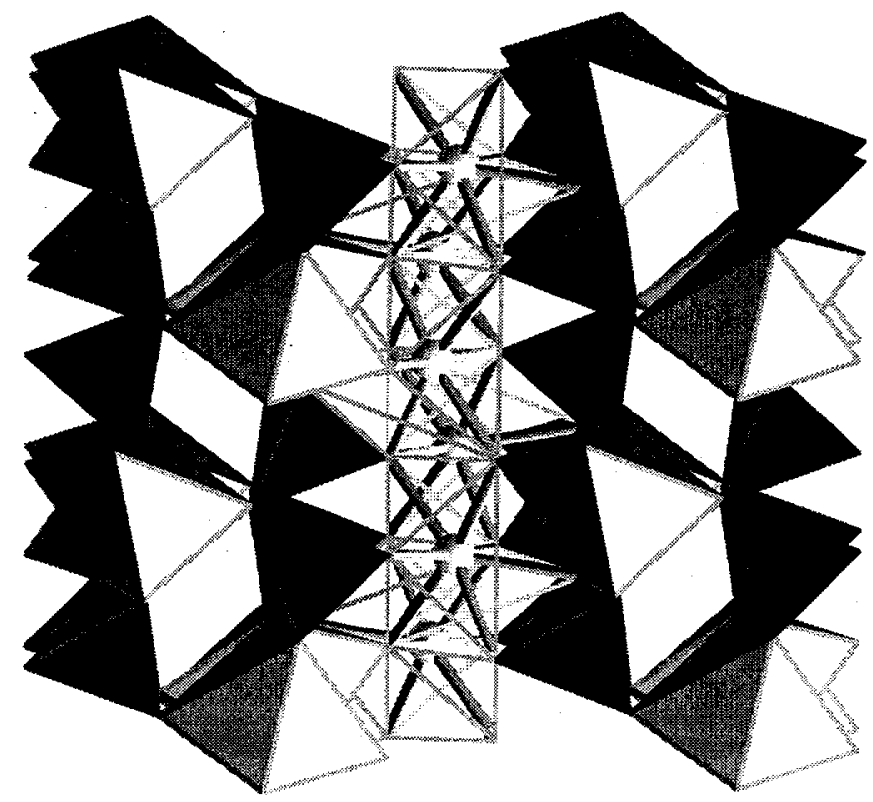

Figure 7. Depiction of the gadolinium orthosilicate phase of the monoclinic $\mathrm{Ln}_{2} \mathrm{SiO}_{5}$ type originally described by Smolin and Tkachev [10]. The Ln occupies two distinct sites, sixfold octahedral sites, rendered as the light polyhedra, and sevenfold decahedral sites, which appear as the central ions with wire frame oxygen polyhedra. The $\mathrm{SiO}_{2}$ tetrahedra are rendered as dark gray, and share three oxygen atoms with the octahedral $\mathrm{Ln}$ and one oxygen with the decahedral Ln.

\section{REFERENCES}

1. D. J. Wronkiewicz, et al., Mat. Res. Symp. Proc. Vol. 294 (1993) 183; D. J. Wronkiewicz, et al., Mat. Res. Symp. Proc. Vol. 333 (1994) 259.

2. A. J. Bakel, C. J. Mertz, D. B. Chamberlain, E. C. Buck, S. F. Wolf, and J. A. Fortner, Proceedings of the $18^{\text {th }}$ International Congress on Glass, San Francisco, July 5-10 1988.

3. N. E. Bibbler, W. G. Ramsey, T. F. Meeker, and J. M. Pareizs, Mat. Res. Symp. Proc. Vol. 412 (1996) 65.

4. T. F. Meaker, D. K. Peeler, J. C. Marra, J. M. Pareizs, and W. G. Ramsey, Mat. Res. Symp. Proc., Vol 465 (1997) 1281.

5. Department of Energy, Record of Decision for the Storage and Disposition of WeaponsUseable Fissile Materials Final Programmatic Environmental Impact Statement 62 FR3014, Office of the Federal Register, Washington D. C., January 14, 1997.

6. G. R. Lumpkin, K. L. Smith, M. G. Blackford, K. P. Hart, P. McGlinn, R. Gieré, and C. T. Williams, Proceedings of the $9^{\text {th }}$ Pacific Basin Nuclear Conference, (Sydney, Australia, May 1-6, 1994).

7. A. B. Kersting, D. W. Eford, D. L. Finnegan, D. J. Rokop, D. K. Smith, and J. L. Thompson, Nature 39756 (1999).

8. International Centre for Diffraction Data, Newtown Square, PA 19073-3273, U.S.A.

9. J. A. Speer and P. H. Ribbe, in Orthosilicates, Reviews in Mineralogy Vol. 5, H. Ribbe, ed. (1982) pp. 429-450.

10. Yu. I. Smolin and S. P. Tkachev, Sov. Phys.-Crystal. 1414 (1969). 